\title{
A Study on Conceptual Design of Fischer-Tropsch Reactors in GTL Applications
}

\author{
Jae Sun Shin, Faraz Qasim, Jong Hwa Jeong and Sang Jin Park \\ Department of Chemical Engineering Dongguk University, 26, Pil-dong 3-ga, Jung-gu, Seoul 100-715, Korea
}

\begin{abstract}
GTL (Gas-to-liquid) process is becoming an attractive technology which can produce liquid petroleum products using natural gas. As a part of preliminary design of GTL-FPSO application, process simulation analysis for conceptual design and optimization of reformers and F-T reactors are performed in GTL-FPSO applications by implementing the user made subroutine programs of kinetic equations into PRO/II PROVISION simulator. As for the F-T reactors, Plug Flow Reactor (PFR) model is used with detailed kinetics equations over two different Fe based catalysts (Fe-Cu-K and K/Fe-Cu-Al). Dry reformer is also studied with Plug Flow Reactor (PFR) model. In this study, simulation results are compared with available experimental data and found well agreed with experimental data for both reformer and FT reactor. The Peng-Robinson equation of state is also used to calculate the vapor phase nonidealities and vapor-liquid equilibrium. The optimum operating conditions and process simulation analysis are also presented.
\end{abstract}

\section{Introduction}

Due to the era of high oil prices recently, the importance of synthetic oil manufacturing technology using natural gas is emerging gradually and the necessity of an environment-friendly fuel leads to the development of BTL (Biomass-to-liquid), CTL (Coal-to-liquid), and GTL (gas-to-liquid) processes. Among many processes for producing synthetic fuel, GTL process for producing synthetic fuel from natural gas has received much attention for eco-friendly fuel which contains less sulfur and aromatic components [1]-[3]. Since the most of gas fields in the world are small and medium-sized, GTLFPSO (Floating Production Storage and Offloading) process can be applied for these fields.

Fischer-Tropsch process was developed in 1920s by Franz Fischer and Hans Tropsch and it plays an important role in conversion of synthesis gases in chemical industries [4]-[6].

The application of GTL-FPSO processes has 4 major steps. First step is the production of synthesis gas (syngas) which consists of carbon monoxide and hydrogen gases by reforming reaction [4]-[7]. Second step is the removal process of carbon dioxide and impurities such as water, nitrogen oxides, and hydrocarbons. Carbon dioxide and other impurities should be removed before F-T reactor, which can cause the low efficiency of F-T reactor. This is because the most of stranded gas fields contain lots of carbon dioxide.

In this work, the conceptual design and optimization of reformer and F-T reactors are focused in GTL-FPSO applications using commercial process simulator (PRO/II with PROVISION release 9.1). In reforming process, natural gas is used as a raw material to produce hydrogen and carbon monoxide which results in $\mathrm{H}_{2} / \mathrm{CO}$ mole ratio of 2. This ratio is known as an optimum condition for F-T synthetic process to produce synthetic fuel $[8,9]$.

\section{Process description}

In dry reforming, there is no water gas shift (WGS) reaction. Only methane and $\mathrm{CO} 2$ are reacted to produce $\mathrm{H} 2$ and $\mathrm{CO}$ as a feed to the F-T process [10]. This reaction can be written in Eq. (1).

$$
\mathrm{CO}_{2}+\mathrm{CH}_{4} \leftrightarrow 2 \mathrm{CO}+2 \mathrm{H}_{2} \quad \Delta \mathrm{H}_{300}^{0}=\frac{247 \mathrm{~kJ}}{\mathrm{~mol}}
$$

As shown in Table 1, operating temperatures and pressures of dry reformer for simulations are changed from $550^{\circ} \mathrm{C}$ to $800^{\circ} \mathrm{C}$ and $1 \mathrm{bar}$ to $30 \mathrm{bar}$, respectively and flowrates of $\mathrm{CO} 2$ and $\mathrm{CH} 4$ are fixed to $100 \mathrm{kmol} / \mathrm{hr}$ while the length of PFR dry reformer varies from 1 to $30 \mathrm{~m}$. A schematic diagram of dry reformer is shown in Fig. 1. In this case, a steady state simulation and optimization are also performed with a plug flow reactor (PFR) and kinetic equations [11] in dry reforming over $\mathrm{Ni} / \mathrm{La} 2 \mathrm{O} 3$ which is described in Table 2. Subroutine program for these kinetic equations is made and implemented in commercial process simulator (PRO/II with PROVISION release 9.1).

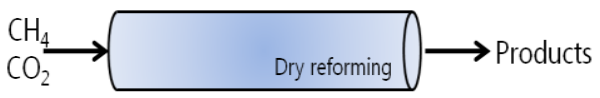

Figure 1. Schematic Diagram of Dry Reformer 
Table 1. Feed Conditions to dry reformer

\begin{tabular}{|c|c|c|c|}
\hline $\begin{array}{l}\text { Reactor } \\
\text { Length }\end{array}$ & $1 \sim 30 \mathrm{~m}$ & $\begin{array}{c}\text { Reactor } \\
\text { Temperature }\end{array}$ & $550 \sim 800^{\circ} \mathrm{C}$ \\
\hline $\begin{array}{l}\text { Reactor } \\
\text { Diameter }\end{array}$ & $0.0653 \mathrm{~m}$ & Reactor Pressure & 1 30bar \\
\hline Flowrate & \multicolumn{2}{|c|}{$\mathrm{CH} 4$} & $\mathrm{O} 2$ \\
\hline$(\mathrm{kmol} / \mathrm{hr})$ & \multicolumn{2}{|c|}{100} & 100 \\
\hline
\end{tabular}

Table 2.Kinetic equation and parameters in dry reforming

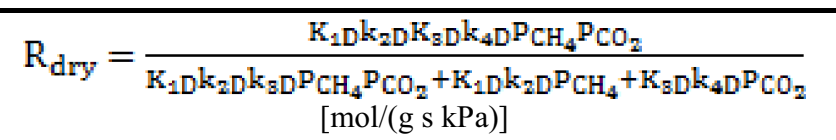

$$
\begin{aligned}
& \mathrm{K}_{1 \mathrm{D}} \mathrm{k}_{2 \mathrm{D}}=2.61 \times 10^{-3} \exp \left(-\frac{4300}{\mathrm{~T}}\right) \\
& {[\mathrm{mol} /(\mathrm{g} \mathrm{s} \mathrm{kPa})]} \\
& \mathrm{K}_{3 \mathrm{D}}=5.17 \times 10^{-5} \exp \left(\frac{8700}{\mathrm{~T}}\right) \\
& \text { [kPa-1] } \\
& \mathrm{k}_{4 \mathrm{D}}=0.531 \exp \left(-\frac{7500}{\mathrm{~T}}\right) \\
& {[\mathrm{mol} /(\mathrm{g} \mathrm{s})]} \\
& \text { reactor }
\end{aligned}
$$

(Experimental data and kinetic equations are taken from reference [11])

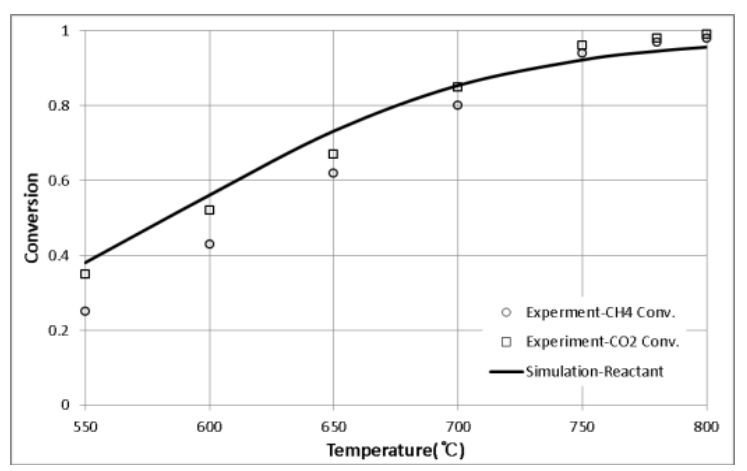

Figure 2. Comparison of experimental data* with simulated conversions of reactants in dry reformer at $1 \mathrm{bar}$ and $\mathrm{CH} 4: \mathrm{CO} 2: \mathrm{He}=2: 2: 6$ (*Experimental data are taken from reference [11])

For the purpose of comparisons, simulated conversions of reactants by using the kinetics equations in Table 2 were based on the same experimental conditions. Experimental

The effect of pressure on the conversion of reactant, for example at $\mathrm{T}=630$, is also analyzed. For operating temperatures lower than $800^{\circ} \mathrm{C}$, reactor length should be increased for a given conversion. For the design of commercial scale of reformer and FT reactors, dimension of reactor could be adjusted depending on the amount of feed for processing, operating conditions, the selection of catalysts, temperature and pressure.

In Fischer-Tropsch reaction, the syngas is converting into paraffins and olefins with a wide range of carbon number including waxy components $(\mathrm{C} 20+)$ over $\mathrm{Fe}$ - or Co- based catalysts by chain growth reactions for producing the transportation oil. According to Wang et.al. [12], the most kinetics of FT reactions over $\mathrm{Fe}$ based catalysts are lumped into groups which failed to reflect the detailed product information. It is known that $\mathrm{Fe}$ based catalyst has several advantages in comparison with Co based catalyst. Fe based catalyst is cheaper than Co based catalyst, and it is less sensitive to impurities in synthesis gas [13-15]. Consequently, the choice of catalysts should be dependent on the economics of the GTL process, the selectivity of product distributions and the operating conditions of the process. In this design of FT reactor, steady state simulations and optimizations are performed with a plug flow reactor (PFR) and two different kinetic equations over $\mathrm{Fe}-\mathrm{Cu}-\mathrm{K}$ (case $\mathrm{A}$ ) and $\mathrm{K} / \mathrm{Fe}-\mathrm{Cu}-\mathrm{Al}$ catalysts (case $\mathrm{B}$ ) by implementing the user made subroutine programs of these kinetic equations into PRO/II PROVISION simulator and comparisons are reported for the both cases.F-T reactor consist of three major reactions such as the formation of paraffins $(\mathrm{CnH} 2 \mathrm{n}+2)$, the formation olefins $(\mathrm{CnH} 2 \mathrm{n})$, and WGS (water gas shift) reactions in the following Eq. (2) to (4).

Paraffin formation

$$
\mathrm{nCO}+(2 \mathrm{n}+1) \mathrm{H} 2 \leftrightarrow \mathrm{CnH} 2 \mathrm{n}+2+\mathrm{nH} 2 \mathrm{O}(\mathrm{n} \geqq 1)
$$

Olefin formation

$$
\mathrm{nCO}+2 \mathrm{nH} 2 \leftrightarrow \mathrm{CnH} 2 \mathrm{n}+\mathrm{nH} 2 \mathrm{O} \quad(\mathrm{n} \geqq 2)
$$

WGS (water gas shift) reaction

$$
\mathrm{CO}+\mathrm{H} 2 \mathrm{O} \leftrightarrow \mathrm{CO} 2+\mathrm{H} 2
$$

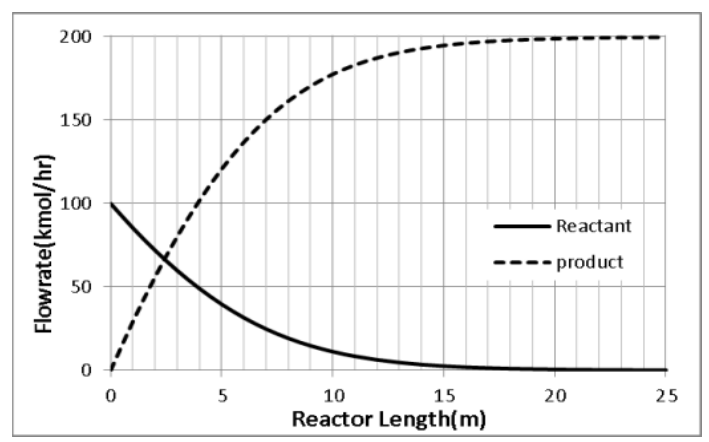

(a)

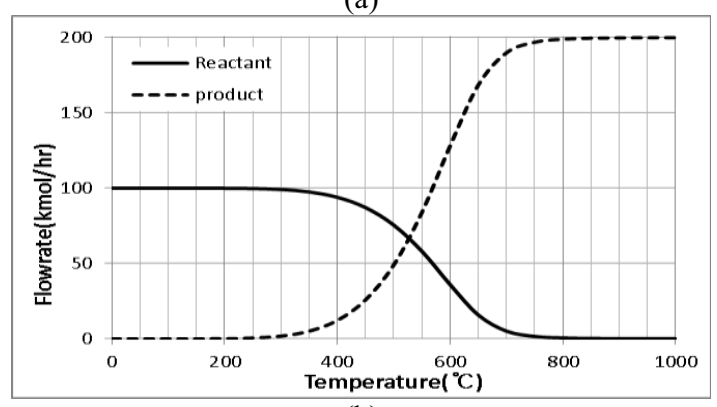

(b)

Figure 3. Flowrates of (a) reactants and products vs. length of reactor at $\mathrm{T}=800^{\circ} \mathrm{C}$ and $\mathrm{P}=1 \mathrm{bar}$ and $(\mathrm{b})$ reactants and products vs. temperature of reactor at $\mathrm{P}=1 \mathrm{bar}$

\section{Results and discussions}

Table 3 enlist the feed and reactor conditions for FT reactor. For the application of GTL-FPSO processes, comparisons of experimental with simulated molar flow rates of products are made by using kinetics model over 
$\mathrm{Fe}-\mathrm{Cu}-\mathrm{K}$ (case A) and $\mathrm{K} / \mathrm{Fe}-\mathrm{Cu}-\mathrm{Al}$ (case B) catalysts for F-T reactor wich are shown in 5 and Fig. 6. It should be noted that experimental molar flow rates of products over $\mathrm{Fe}-\mathrm{Cu}-\mathrm{K}$ (case A) catalyst are cumulatively taken with a period of 10-15 h during steady state of FT micro reactor system with the diameter of $18 \mathrm{~mm}$ and the length of 300 $\mathrm{mm}$ at $\mathrm{T}=533.15 \mathrm{~K}, \mathrm{P}=20.92$ bar for very small amounts of feeds with the ratio of $\mathrm{H}_{2} / \mathrm{CO}=1.88$. For case $\mathrm{B}$, experimental data [17] over $\mathrm{K} / \mathrm{Fe}-\mathrm{Cu}-\mathrm{Al}$ catalyst is generated under the conditions with the diameter of 22 mm-i.d. and the length of $1 \mathrm{~m}$ at $\mathrm{T}=523.15 \mathrm{~K}, \mathrm{P}=10 \mathrm{bar}$ for very small amount of feed with the ratio of $\mathrm{H}_{2} / \mathrm{CO}=1.5, \mathrm{SV}=2,000 \sim 8,000 / \mathrm{h}$. For the purpose of comparisons, predicted molar flow rates of products by simulations are based on the same operating conditions such as temperature, pressure, feed ratio of $\mathrm{H}_{2} / \mathrm{CO}$, and reactor scale. It is evident from Fig. 4 that the experimental data from the reference agrees well with the simulated data in the present work and there are small deviations between experimental and simulated data.Fig. 5 shows an inverse relation between carbon number and the flow rate. It can be observed that the carbon number get increased if the flow rate is decreased.

Furthermore, the hydrogen to carbon monoxide ratio is about 2 which agrees well with the process requirements. Fig. 6 shows the same behavior for paraffin and olefin. In Fig. 6, the two cases A \& B are compared on the basis of flow rate vs carbon number at $\mathrm{P}=20.92 \mathrm{bar}$, $\mathrm{T}=523.15 \mathrm{~K}$, tube length $=10 \mathrm{~m}$ and diameter of tube $=0.0653 \mathrm{~m}$. According to Fig. 5 and Fig. 6, all simulated flow rates of products are generally well agreed with experimental data. Comparisons should focus on the trends of product distributions and was shown in similar distribution of products of functional relationship of the carbon numbers. However, though the experimental data for case B seems to be rather inconsistent due to experimental errors, overall comparisons are in acceptable ranges and similar tendency. In Fig. 6, conversions of $\mathrm{H}_{2}$ and $\mathrm{CO}$ increases monotonically as the length of reactor increases for both cases at $\mathrm{P}=20.92$ bar and $\mathrm{T}=523 \mathrm{~K}$. The conversions of $\mathrm{CO}$ and $\mathrm{H}_{2}$ are 0.626 and 0.641 for case $\mathrm{A}$ and the conversions of $\mathrm{CO}$ and $\mathrm{H}_{2}$ are shown as 0.720 and 0.756 for case B. Fig. 6 shows that conversions of $\mathrm{CO}$ and $\mathrm{H}_{2}$ for case $\mathrm{B}$ are more greater than those for case A.

It is known that existing FT reactors in SASOL processes in South Africa are operating normally in the range of temperature $\mathrm{T}=350 \mathrm{~K} \sim 523 \mathrm{~K}$ for LTFT (Low Temperature Fisher-Tropsch) reaction and temperature $\mathrm{T}=573 \mathrm{~K} \sim 623 \mathrm{~K}$ for HTFT (High Temperature FisherTropsch) reaction at pressure $\mathrm{P}=20 \sim 21$ bar. For the purpose of conceptual design of GTL processes, simulations of FT reactor are performed for two different temperatures $\mathrm{T}=523 \mathrm{~K}$ and $\mathrm{T}=623 \mathrm{~K}$ at $\mathrm{P}=20.92$ bar even though kinetic parameters for both catalysts $\mathrm{A}$ and $\mathrm{B}$ are optimized in the range of $\mathrm{T}=483 \mathrm{~K} \sim 563 \mathrm{~K}$. Simulated results for $\mathrm{T}=623 \mathrm{~K}$ lie out of the experimental range of temperature but those could be used for interpretation of the effect of HTFT reaction on product distributions from FT reactor.

In this work, simulation results for the FT reactor exhibit that the conversion of the carbon monoxide and hydrogen increases if the operating temperature increases. Same behavior is observed by increasing pressure too. The different combinations of the catalysts are analyzed in this study and the proposed study can lead to a compact and conceptual design of Fischer Tropsch reactors in GTL applications.

Interpretation of the products distribution and selectivity of products can also be done by normalization of products of $\mathrm{C}_{1}$ to $\mathrm{C}_{5}+$ excluding the products of $\mathrm{CO}$, $\mathrm{H}_{2} \mathrm{O}, \mathrm{H}_{2}$, and $\mathrm{CO}_{2}$ assuming the amount of wax formation.

In summary, for both cases $\mathrm{A}$ and $\mathrm{B}$, more olefins are produced than paraffins and conversions of $\mathrm{CO}$ and $\mathrm{H}_{2}$ increase as operating temperature and pressure increase which are corresponded to results. In addition, the length of reactor tube should be increased as the diameter of reactor tube decreases for the same conversion of $\mathrm{CO}$ and $\mathrm{H}_{2}$.

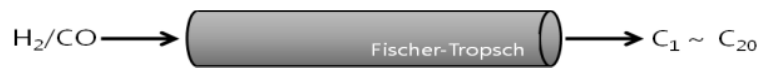

Figure 4. Schematic diagram of F-T reactor

Table 2. Feed and reactor conditions to F-T reactor

\begin{tabular}{|c|c|c|c|c|c|c|}
\hline \multicolumn{2}{|c|}{$\begin{array}{l}\text { Flowrate } \\
(\mathrm{kmol} / \mathrm{hr})\end{array}$} & \multicolumn{5}{|c|}{ Reactor condition } \\
\hline $\mathrm{CO}$ & $\mathrm{H} 2$ & $\begin{array}{c}\text { Pressu } \\
\text { re } \\
\text { (bar) }\end{array}$ & $\begin{array}{c}\text { Temp } \\
\text { eratur } \\
\mathrm{e} \\
(\mathrm{K})\end{array}$ & $\begin{array}{c}\text { Lengt } \\
\mathrm{h} \\
(\mathrm{m})\end{array}$ & $\begin{array}{c}\text { Tube } \\
\text { numb } \\
\text { er }\end{array}$ & $\begin{array}{c}\text { Diam } \\
\text { eter } \\
(\mathrm{m})\end{array}$ \\
\hline 100 & 200 & $1 \sim 30$ & $\begin{array}{c}473 \\
\sim 1453 \\
.15\end{array}$ & $\begin{array}{c}1 \sim 10 \\
\mathrm{~m}\end{array}$ & 5 & $\begin{array}{c}0.065 \\
3 \mathrm{~m}\end{array}$ \\
\hline
\end{tabular}

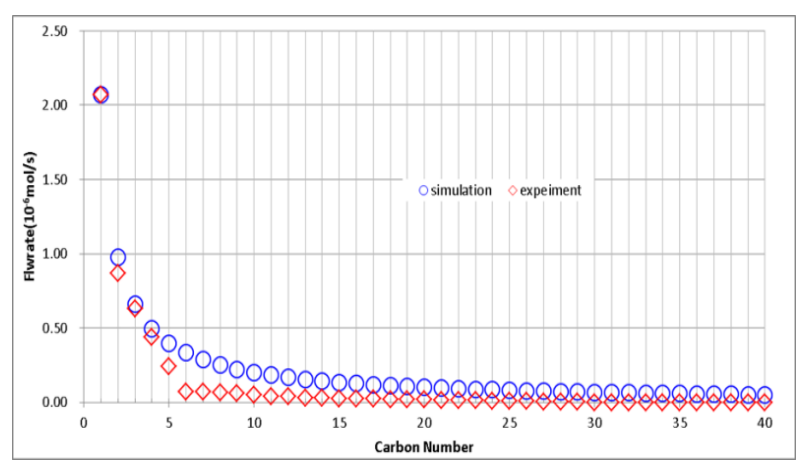

Figure 5. Comparisons of simulation and experimental data* (case A) according to carbon numbers at 533.15K, 20.92bar, and at the feed ratio of $\mathrm{H} 2 / \mathrm{CO}=1.88$ (*Experimental data is taken from reference [16])

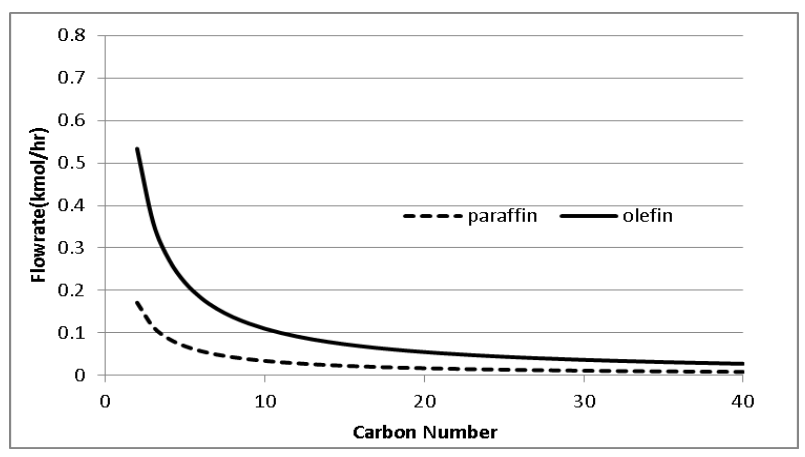

(a) 


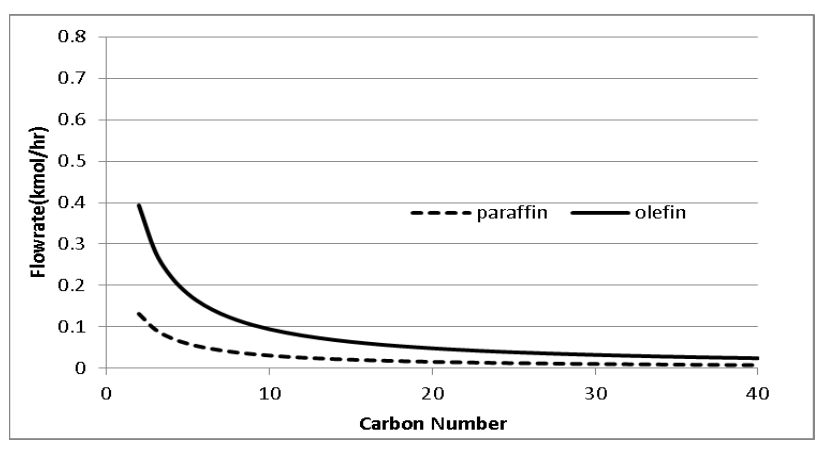

(b)

Figure 6. Comparison of the formation of olefins and paraffins vs. carbon numbers at $\mathrm{P}=20.92 \mathrm{bar}, \mathrm{T}=523.15 \mathrm{~K}$, and tube length $=10 \mathrm{~m}$ and diameter of tube $=0.0653 \mathrm{~m}$ where (a) is for Case A and (b) is for Case B

\section{Conclusions}

For the purpose of conceptual design of GTL processes, simulations of dry reformer and FT reactor are performed. For FT reactor simulation is done for two different temperatures $\mathrm{T}=523 \mathrm{~K}$ and $\mathrm{T}=623 \mathrm{~K}$ at $\mathrm{P}=20.92$ bar even though kinetic parameters for both catalysts $\mathrm{A}$ and $\mathrm{B}$ are optimized in the range of $\mathrm{T}=483 \mathrm{~K} \sim 563 \mathrm{~K}$. Simulation results for FT reactor show that more olefins are produced than paraffins and conversions of $\mathrm{CO}$ and $\mathrm{H}_{2}$ over two different catalysts increase as operating temperature and pressure increase. For the dry reformer, the steady state simulations are performed with exact kinetics equations and optimum operating conditions and reactor scales are reported too. Overall, proposed simulation study can provide the tool for the effective conceptual design of reformer and FT reactor for various catalysts, reactor types and scale, and different operating conditions based on kinetic equations by integrating all GTL processes.

\section{References}

1. Y. H. Kim, K. Y. Koo and I. K. Song, Simulation Study on SCR(Steam Carbon Dioxide Reforming Process Optimization for Fischer-Tropsch Synthesis, Korean Chem. Eng. Res., 47, 700-704 (2009).

2. J. R. Rostrup-Nielsen, Production of Synthesis Gas, Catal. Today, 18, 305-324 (1993).

3. C. Nottenbelt, Mossgas Gas-to-Liquid Diesel FuelsAn Environmentally Friendly Option, Catal. Today, 71, 437-445 (2002).

4. W. Maqbool \& E. S. Lee. Syngas Production Process Development and Economic Evaluation for
Gas - to - Liquid

Applications. Chemical Engineering \& Technology, 37, 995-1001 (2014).

5. T. Takeshita, K. Yamaji, Important roles of FischerTropsch synfuels in the global energy future. Energy Policy, 36, 2773-2784 (2008).

6. M. E. Dry, The Fischer-Tropsch Processes, Catal. Today, 71, 227-241 (2002).

7. A.N. Pinheiro, A. Valentini, J.M. Sasaki, A.C. Oliveira, Highly stable dealuminated zeolite support for the production of hydrogen by dry reforming of methane, Appl. Catal. A, 355, 156-168 (2009).

8. D. J. Wilhelm, Simbeck, S. R. Karp, A. D. and Dickenson, R. L., Syngas Production for Gas-toLiquids Applications: Technologies, Issues and Outlook, Fuel Process Technol., 71, 139-148 (2001).

9. X. Hao, "Simulation Analysis of a Gas-to-Liquid Process Using Aspen Plus", Chem. Eng. Technol., 31, 188-196 (2008).

10. DL Trimm, The formation and removal of coke from nicket catalyst, Catal Rev-Sci Eng. 16, 155-189 (1977).

11. XE Verykio, Catalytic dry reforming of natural gas for the production of chemicals and hydrogen, International Journal of Hydrogen Energy, 28, 1045 - 1063 (2003).

12. J.R. Rostrup-Nielsen, Syngas in perspective, Catal. Today 71, 243-247 (2002).

13. Aasberg-Petersen, K., Bak Hansen, J.-H., Christensen, T. S., Dybkjaer, I., Christensen, P. S., Nielsen, C. S., Winter Madsen, S. E. L. and RostrupNielsen, J. R., Technologies for Large-Scale Gas Conversion, Appl. Catal. A, 221, 379-387 (2001).

14. Y. Yang, H.W. Xiang, R.L. Zhang, B. Zhang, Y.W. $\mathrm{Li}$, A highly active and stable Fe-Mn catalyst for slurry Fischer-Tropsch synthesis, Catalysis Today, 106, 170-175 (2005).

15. A.K. Dalai and B.H. Davis, Fischer-Tropsch synthesis: A review of water effects on the performances of unsupported and supported Co catalysts, Applied Catalysis A: General, 348, 1-15 (2008).

16. Y. J. Lee, S. I. Hong, D, J, Moon, Studies on the steam and $\mathrm{CO} 2$ reforming of methane for GTLFPSO applications, Catalysis Today, 174, 31- 36 (2011).

17. Y. H. Kim, D. Y. Hwang, S. H. Song, S. B. Lee, E. D. Park, and M. J. Park, Kinetic parameter estimation of the Fischer-Tropsch synthesis reaction on $\mathrm{K} / \mathrm{Fe}-\mathrm{Cu}-\mathrm{Al}$ catalysts, Korean J. Chem. Eng., 26, 1591-1600 (2009). 